\title{
Espinoza e a linguagem ${ }^{1}$
}

Espinoza and the Language

Olga Pombo

Doutora em História e Filosofia da Educação pela Universidade de Lisboa, Portugal. Professora da Faculdade de Ciências da Universidade de Lisboa, Portugal. E-mail: opombo@fc.ul.pt

Não há uma "teoria” desenvolvida da linguagem no sistema de Espinoza. A linguagem não é um problema que Espinoza tenha seleccionado como merecedor de ser pensado. $\mathrm{Na}$ filosofia de Espinoza, os problemas da linguagem não encontram um lugar sistemático. Espinoza nunca se situa face à tradição de reflexão sobre a linguagem que o antecede ou lhe é contemporânea, nem estabelece qualquer tipo de relação arquitectónica que integre as suas teses sobre a linguagem com alguns outros lugares do seu pensamento. Como Espinoza (1972) escreve de forma clara e categórica: "Mas o meu propósito é explicar, não o

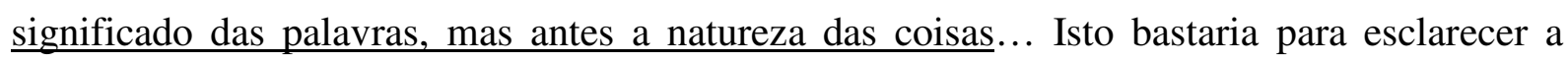
questão uma vez por todas (Ethica 3Def20, nossos sublinhados)".

No entanto, sob a forma de enunciados dispersos e não sistemáticos, há em Espinoza algumas teses importantes sobre a linguagem, profundas reflexões, notas subtis e observações luminosas. Em dois momentos precisos, ou melhor, em duas direcções da sua actividade intelectual, Espinoza é como que forçado a dar atenção aos problemas da linguagem: uma diz respeito à sua necessidade de construir uma exegese racional das Sagradas Escrituras; outra surge das questões colocadas no quadro da sua teoria do conhecimento. A primeira tem lugar no Tractatus Theologico-Politicus (TTP); a segunda emerge, sobretudo, na Ethica (E), no Tractatus de Intellectus Emendatione (TIE) e, também, em Korte Verhandeling.

\section{Aproximação Exegética}

A primeira direcção ocorre em contexto hermenêutico, mais exactamente quando, nos capítulos teológicos de TTP, Espinoza propõe o exame dos livros sagrados, unicamente através de uma crítica histórica e filológica, livre de qualquer restrição dogmática e pressuposição teológica. No cumprimento dessa tarefa, Espinoza começa por estabelecer o próprio método exegético que se propõe adoptar.

\footnotetext{
${ }^{1}$ Texto retomado do nosso estudo intitulado "Leibniz e Espinosa sobre temas da Linguagem", in Olga Pombo (2010: p. 143-173).
}

InCID: R. Ci. Inf. e Doc., Ribeirão Preto, v. 2, n. 1, p. 16-30, jan./jun. 2011. 
No capítulo 7 - um verdadeiro "discurso do método em matéria de exegese”, como diz Gusdorf (1988, p. 112) - encontramos a exposição detalhada desse método, fundamentalmente, constituído por três ordens de requisitos:

1. requisitos etimológicos e morfológicos relativos à especial atenção que deve ser dada à: "natureza e propriedades da linguagem na qual os livros da Escritura foram escritos" (TTP 7, 3: 99);

2. requisitos estruturais internos, relacionados com a necessidade de

\begin{abstract}
organizar em diferentes grupos os enunciados de cada livro, reduzindo-os a algumas chaves fundamentais, como modo de encontrar, com facilidade aqueles que se relacionam com o mesmo objecto (e)... aqueles que são ambíguos ou obscuros ou em contradição uns com os outros (TTP 7, 3: 100);
\end{abstract}

3. requisitos externos, históricos e filológicos, relacionados com a investigação da vida e dos costumes do autor de cada livro, sobre os seus objectivos e propósitos, sobre o tempo, a ocasião e outras circunstâncias particulares da composição dos manuscritos, do seu destino e história posterior, etc. (TTP 7, 3: 101-102)

Ora, é justamente no contexto deste programa exegético, que Espinoza é compelido a tratar alguns dos temas clássicos de reflexão sobre a linguagem, tais como os conceitos de leitura, tradução, interpretação alegórica e literal, linguagem metafórica e poética, linguagem popular e religiosa, intenção significativa do autor, estilo, significação, contexto.

Tomemos o caso de um destes temas - uma concepção original de significado que, apesar de restrita aos livros sagrados, é extremamente interessante e próxima da "viragem hermenêutica" que caracteriza a nossa contemporaneidade.

\title{
O "significado" em TTP
}

Espinoza começa pela distinção entre conhecimento natural e conhecimento revelado. Enquanto o primeiro, apesar de divino na sua raiz, advém de um conjunto de princípios da luz natural aos quais todos os homens dão consentimento livre e total, o conhecimento revelado é alcançado pelos homens através da mediação de um profeta, ou seja, de um "intérprete das revelações de Deus" (TTP 1: 15), um tradutor, alguém que recebe a Palavra de Deus, que a compreende à sua medida, que a traduz numa língua vulgar, e que comunica aos outros aquilo 
que foi capaz de compreender ${ }^{2}$. Como Espinoza escreve, "assim, o conhecimento revelado é já discurso, discurso humano que, unicamente através do prestígio do profeta e confiança que as pessoas lhe dedicam" (TTP 1, Adn2), isto é, pode ser escutado por outros, permanecer, perdurar através dos séculos, sob forma de tradições orais e escritas.

Ora - observa Espinoza -, dado que já não existem hoje mais profetas que pudessem ser ouvidos de modo directo, temos que nos contentar com os textos antigos deixados pelos antigos profetas (TTP 1, 3: 6). Tudo o que temos está lá, "fechado", nos textos do Antigo Testamento, guardado nas palavras (signos ambíguos e equívocos) de uma língua vulgar e plebeia - o hebreu. Não há autoridade externa a que possamos recorrer, nenhuma doutrina arbitrária, nenhum constrangimento dogmático, nenhuma invenção humana que deva ser respeitada (TTP 7, 3: 97). Como Espinoza afirma: "todo o conhecimento da Escritura deve ser retirado somente da própria Escritura." (TTP 7, 3: 99)

Neste enunciado de importância central, Espinoza defende a tese clássica da autonomia da letra face ao espírito, tese que é, obviamente, rica em consequências exegéticas, nomeadamente, na oposição a todos os métodos alegóricos de interpretação das Escrituras ${ }^{3}$. Mas, o que gostaríamos de enfatizar é o facto de que tal enunciado é também rico quanto ao conceito de significado que Espinoza terá de trabalhar de modo a encontrar-lhe um fundamento sólido. Quer dizer, se o propósito daquele enunciado ("todo o conhecimento da Escritura deve ser retirado somente da própria Escritura”) é exegético, a sua defesa implicará a formulação, ou melhor, a "invenção" 4 , por Espinoza, de um novo conceito de significado. E, nesse novo conceito de significado está suposto que: 1 . o significado é interno ao texto; 2 . o lugar do significado não é a letra (como os cabalistas queriam), nem a palavra e a frase (como no caso de Leibniz), mas o texto, somente o texto.

Espinoza enfatiza muito esta interessante tese. Repete-a várias vezes, quase sempre na mesma formulação. O significado não é algo que o leitor possa reactualizar em diferentes épocas, consoante a sua própria visão ou compromisso privado com o texto ${ }^{5}$. Para Espinoza, o significado está fechado nas Escrituras, desde o primeiro momento da sua escrita pelos

\footnotetext{
${ }^{2}$ O conhecimento revelado é, portanto, uma tradução humana da Palavra de Deus, a qual consiste num só e único percepto - a prática da justiça e da caridade. Note-se também que tal significado provém do texto das Escrituras como um todo.

${ }^{3}$ Nomeadamente, o método alegórico de Maimonides. Cf. TTP 7, 3: 113 e segs.

${ }^{4}$ Usamos aqui uma expressão de Zac (1977: 623) que a qualifica até de "grande invenção".

${ }^{5}$ Algo que, como Lévinas (1982: 201-206) afirma, é contraditório com toda a tradição talmúdica, assim como com o nosso sentimento hermenêutico contemporâneo, segundo o qual o leitor do texto tem um papel decisivo na produção do significado do texto.
}

InCID: R. Ci. Inf. e Doc., Ribeirão Preto, v. 2, n. 1, p. 16-30, jan./jun. 2011. 
profetas antigos. Por isso, é no próprio texto, unicamente através da lógica interna do texto, que devemos interpretar o significado de um enunciado.

\section{Significado e Método Exegético}

Como vimos acima, o primeiro requisito metodológico defendia a necessidade de um conhecimento profundo da língua na qual os livros da Escritura foram escritos para ser possível levar a cabo a sua adequada exegese.

Trata-se de um requisito que pode ser visto como contraditório com a regra acima referida, no sentido em que o significado do texto seria, de certo modo, exterior ao texto, baseando-se não no texto, mas na língua em que o texto é escrito. Mas, por outro lado, este requisito pode também ser visto como uma consequência necessária daquela regra: o significado do texto é interno ao texto e, portanto, à língua na qual o texto está escrito. E isto na medida em que um texto não é mais do que um fragmento, ou melhor, uma expressão, uma das possíveis manifestações da língua em que está escrito.

Uma dificuldade maior ocorre quando Espinoza, vendo que a língua original das Escrituras era fundamentalmente o hebreu - língua da qual, como diz, não temos: "nem sequer um dicionário, nem uma gramática (...), mas só fragmentos da linguagem e poucos livros" (TTP 7, 3: 106) -, conclui que "é impossível ter um conhecimento histórico perfeito do hebreu" (ibid.). Além disso, dado que o hebreu é, também, uma língua na qual existem muitas causas particulares de ambiguidade (que Espinoza assinala e descreve), Espinoza conclui que não há nenhum método que permita determinar o verdadeiro significado de uma passagem ambígua da Escritura (TTP 7, 3: 107).

Estamos pois perante uma conclusão que parece comprometer o princípio da interpretação da Escritura apenas pela Escritura. No entanto, se não estamos em erro, é possível interpretar esta mesma questão da seguinte forma:

1. se esses textos existissem, isto é, dicionários, gramáticas, literatura em geral, seria neles e por eles que poderíamos ter um conhecimento perfeito da língua;

2. o conhecimento da língua - neste caso, o hebreu - só pode ser obtido, não pelo facto de que alguém fale essa língua, mas pelo conhecimento de um conjunto de textos nos quais a língua existe - dicionários, gramáticas, literatura. Caso contrário, seria sempre 
possível, para um falante da língua, descobrir ou, mesmo, decifrar o significado de palavras antigas e expressões idiomáticas; haveria uma criatividade heurística da própria língua que tornaria isso possível (algo que Espinoza não pode aceitar, tendo em vista aquilo que afirma sobre as dificuldades inultrapassáveis de um conhecimento perfeito do hebreu);

3. quer esses textos existam ou não - como no caso do hebreu -, seria, então, o conhecimento desses textos que forneceria o conhecimento da língua e, por isso (contrariamente, outra vez, àquilo que o primeiro requisito metodológico parecia afirmar), a linguagem não é, nela mesma, a verdadeira e última (e externa) raiz do significado, uma raiz para a qual poderíamos apelar para descobrir o significado do texto (neste caso, da Escritura);

4. generalizando, poderíamos dizer: o significado do(s) texto(s) não deve ser pensado no significado que a língua guarda em si mesma, mas, pelo contrário, é o significado da língua que deve ser descoberto no e através do significado do(s) texto(s).

Estamos pois perante um conjunto de teses que, de facto, reforçam esta interessante concepção espinosista do significado de acordo com a qual o significado habita unicamente o interior do texto.

\section{Verdade e Significado}

No entanto, é importante perguntar: porquê uma tal tese? Qual era o problema que esta tese tentava enfrentar?

De modo a procurar uma resposta para estas interrogações, devemos lembrar que, para Espinoza, a Escritura apela unicamente à fé, à obediência (TTP Prae, 3: 10). Assim sendo, a única coisa que o homem precisa de saber sobre a Escritura é se interpretou bem o que ela afirma, se compreendeu correctamente o que ela ordena, se apreendeu adequadamente aquilo a que deve obedecer. Por outras palavras, o homem não precisa de averiguar a verdade de tais ordens. Quer isto dizer que a Escritura não é, portanto, para ser interpretada na sua "verdade", mas só no seu "significado". 
Esta distinção fundamental é claramente expressa por Espinoza nos seguintes termos: "só procuramos aqui o significado do texto e não a sua verdade." (TTP 7, 3: 100). Mais adiante, Espinoza acrescenta:

(...) é necessário, quando procuramos o significado da Escritura, não ter a mente preocupada com o nosso raciocínio, o qual está fundado nos princípios do conhecimento natural (...) de modo a não confundir o verdadeiro "significado" (de um discurso) com a "verdade" das coisas. (ibid., sublinhados nossos.)

A verdade é a tarefa do filósofo, mas não a do crente que está unicamente interessado em conhecer aquilo a que é suposto obedecer, aquilo que Deus quer que ele faça. O que importa a Espinoza é o estatuto que é necessário garantir ao uso pragmático da Escritura.

Estaremos aqui face a uma outra concepção do significado segundo a qual o critério para a avaliação de uma correcta interpretação do significado de um texto (de um texto normativo, como no caso das escrituras), é o comportamento correspondente que esse texto induz alguém a realizar, neste caso, o comportamento da obediência? Estaremos aqui perante uma outra "invenção espinosista", desta vez, não uma concepção imanentista, mas uma concepção pragmática do significado?

De qualquer modo, o princípio espinosista de interpretação da Escritura, exclusivamente, pela Escritura, mesmo que confinado ao contexto exegético dos livros da Escritura nos quais, de facto, é formulado, tem o mérito de chamar a atenção para a possibilidade de o significado estar alojado, não no nível semântico do signo, da palavra ou da frase, mas no nível arquitectónico do texto, razão pela qual denominámos essa concepção como imanentista.

\section{Aproximação Gnosiológica}

Uma das teses espinosistas mais importantes é a concepção segundo a qual a linguagem é, não só o grau inferior (imaginativo, confuso, inadequado) do conhecimento, mas também um obstáculo ao verdadeiro conhecimento, o qual "se faz manifesto por si só" (TIE: 44), não precisa de nenhuma palavra, isto é, a concepção segundo a qual a linguagem é, não apenas causa de ambiguidades e de mal entendidos de todas as espécies, mas o próprio “veículo do engano", como diz Guéroult (1974, p. 434), veículo esse que não pode ser eliminado, mas unicamente diminuído ou atenuado. 
Com esta tese, que vem sobretudo de Bacon e Descartes, Espinoza está em completa oposição com Leibniz. Enquanto, para Espinoza, há uma clara distinção a fazer entre imaginatio e ratio, para Leibniz, a única diferença é de graduação, uma vez que, sendo ambas elementos constitutivos de uma série contínua de percepções, elas apenas diferem uma da outra pelo grau de clareza e distinção. Além disso, enquanto para Espinoza a imaginatio é a causa da falsidade e ratio a causa do conhecimento necessariamente verdadeiro, pelo contrário, para Leibniz, toda a percepção contém ou envolve uma infinidade de "petites perceptions", relativamente obscuras, confusas e inconscientes, ou seja, imaginação e entendimento são elementos necessariamente inseparáveis, pressupostos um pelo outro. Como Leibniz diz, "os pensamentos mais abstractos precisam de alguma imaginação" (GP 4: 563).

No entanto, é importante notar que Leibniz estava, neste ponto, em oposição a todos os seus contemporâneos. De facto, no século XVII, só Leibniz percebeu, em todas as suas consequências epistémicas, o papel decisivo da linguagem na constituição e progresso do conhecimento científico, ou seja, só Leibniz reconheceu que a linguagem não perturba o conhecimento da realidade, mas, pelo contrário, leva à sua penetração racional, não apenas reflectindo, mas também promovendo e clarificando o conhecimento da realidade. Como Leibniz diz, em Carta a Tschirnhaus, de Maio, 1679: "ninguém deve temer que a contemplação de caracteres nos possa levar para longe das coisas; pelo contrário, ela conduznos ao interior das coisas. (ad intima rerum ducet)" (GM 4: 461)

De facto, Leibniz é detentor de uma importante e rara concepção cognitiva da linguagem. Com excepcional clareza, Leibniz reconheceu e proclamou a importância cognitiva e heurística do simbolismo que considera ser o meio próprio, necessário e essencial da razão humana, aquilo que nos permite operar com significações ideais que só podem ser estabelecidas por signos e que só os signos - como símbolos das determinações virtuais das nossas ideias - permitem pensar. Como Leibniz escreve, nos célebres Dialogus de Connexione inter Res et Verba, de 1677: "nunca serei capaz de saber, de descobrir, de provar sem usar palavras ou sem a presença na minha mente de outros signos.” (GP 7: 191)

Ainda que estejamos perante uma das passagens onde esta tese está mais claramente expressa $^{6}$, é irrefutável que Leibniz estava completamente consciente do campo inesgotável

\footnotetext{
${ }^{6}$ A posição de Leibniz não é, de facto, sempre tão fortemente expressa como na passagem citada acima. Compelido pelos limites epistemológicos e linguísticos do século XVII, assim como pelas aporias da sua própria teoria do simbolismo, Leibniz evitou algumas vezes uma forte defesa desta tese. A sua posição está marcada por certas ambiguidades que dizem respeito ao estatuto efectivo conferido ao signo. Cf. Pombo (1997: 125-161).
} 
das possibilidades cognitivas, abertas pelo uso do simbolismo, ou seja, do poder não meramente judicativo ou demonstrativo do simbolismo, mas também das suas possibilidades prospectivas e heurísticas.

Espinoza, pelo contrário, segue a tese usual do seu tempo, uma tese vinda quer do cepticismo inglês (interessado em aprofundar os obstáculos ao conhecimento), quer do intuicionismo francês (interessado em defender o papel meramente instrumental e comunicativo da linguagem). Tese, em geral, defendida por toda a filosofia moderna, a qual tinha estabelecido uma ruptura, porventura, demasiadamente profunda com as inspirações renascentistas e com o sentido analógico da sua sabedoria. Uma tese que, no caso de Espinoza, era necessária para salvaguardar a absoluta completude do conhecimento intuitivo divino. Ou seja, a oposição entre Leibniz e Espinoza quanto a este importante tema, mesmo que óbvia e "trenchant", parece-nos não ser completamente relevante, uma vez que, neste ponto, Leibniz estava em oposição ao seu tempo, muito para lá dos limites epistémicos da sua época. Isso pode, de facto, acontecer em filosofia, mesmo que seja só aí que os homens consigam ir para além das suas fronteiras (temporais).

\section{Arbitrariedade da Linguagem Humana}

Prestemos agora atenção a outro importante tema, igualmente emergente nesta segunda direcção gnosiológico. Referimo-nos à questão fundamental da arbitrariedade versus não-arbitrariedade da linguagem humana.

O paralelo com Leibniz é aqui extremamente esclarecedor. Ao ler as passagens de Espinoza sobre a linguagem, ficamos admirados pelo aparecimento de tantas questões importantes e interessantes que, repentinamente, o génio de Espinoza encontra e reconhece. Mas, dado que o seu maior interesse não está aí, ele dá-lhes uma rápida solução - mesmo que profunda - e segue em frente. Reconhece a questão, formula sobre ela uma frase breve e decisiva, e abandona-a. Leibniz, pelo contrário, durante toda a sua produção intelectual lida intencionalmente com os problemas da linguagem que verdadeiramente o interessam, discute várias hipóteses para a sua solução, estima as suas respectivas consequências, aprecia os seus fundamentos.

Assim, depois de ter afirmado (TIE: 88) que as palavras, como a imaginação, podem ser a causa de muitos e sérios erros, Espinoza deixa cair, no parágrafo que se segue, a seguinte 
afirmação: "De acrescentar que as palavras são constituídas arbitrariamente, de acordo com as pessoas comuns." (TIE: 89) Note-se que esta tese, que faz a sua aparição no texto de Espinoza de um modo tão repentino, é formulada uma única vez em todo o TIE. Note-se, ainda, que esta tese poderia ser um forte argumento e uma excelente oportunidade para Espinoza justificar a concepção negativa da linguagem que tinha acabado de defender no parágrafo anterior (TIE: 88). Poderíamos, portanto, esperar que Espinoza desse maior atenção a uma tese tão fundamental. Mas ele não o faz.

É certo que há outras passagens que podem ser relacionadas com esta, por exemplo, aquela onde Espinoza diz que os livros, sendo conservados por homens instruídos, podem ser corrompidos, enquanto a língua, sendo conservada pelos livros e também pelo povo, não pode ser corrompida. Quer dizer que o povo é considerado como o garante da incorruptibilidade da língua (TTP 7, 3: 105-106), o que poderia ser lido como uma espécie de elogio indeterminado ao povo anónimo e ao seu poder onomatúrgico, ou seja, uma espécie de reafirmação da posição convencionalista de Espinoza, agora como que acompanhada pelo começo de uma explicação acerca da natureza desse convencionalismo (aqui pensado na sua dimensão social e institucional). Na Ethica há ainda uma outra passagem na qual Espinoza, sem sequer mencionar a arbitrariedade da linguagem humana, de certo modo, aponta uma explicação complementar para essa arbitrariedade, aí pensada, menos de um ângulo sociológico que de uma perspectiva psicológica. É quando Espinoza explica que a razão para os erros resultantes do uso das palavras tem a sua origem no hábito, segundo o qual as pessoas dão nomes aos modos particulares e subjectivos pelos quais são afectadas por corpos exteriores (E: 47S).

No entanto, é claro que Espinoza não está, realmente, interessado na questão da arbitrariedade das línguas humanas. Ela é justamente exemplo de uma dessas questões que Espinoza encontra no decorrer do seu percurso, à qual dá uma resposta conclusiva, sobre a qual adquire consciência das dificuldades em jogo, mas que também facilmente abandona para seguir o seu caminho.

\section{Locke e Leibniz}

Pelo contrário, Leibniz trabalhou esta questão durante toda a sua actividade intelectual, explorou quase todas as direcções possíveis, examinou múltiplas perspectivas paralelas, perseguiu linhas de investigação diferentes, divergentes e, aparentemente, 
contraditórias. Como se Leibniz, estando de tal modo consciente do papel central dessa questão para a compreensão da essência da linguagem humana, sentisse claramente como cada resposta - e todas elas em conjunto - era incapaz de esgotar os mistérios da linguagem.

É assim que, naquele que é, significativamente, o mais longo parágrafo dos Nouveaux Essais (III, III, § 1), Leibniz refuta a posição convencionalista da filosofia da linguagem de Locke. A disputa surge, fundamentalmente, da oposição que Leibniz estabelece à tese, apresentada por Philalethe, das múltiplas imperfeições que são inerentes às linguagens humanas, ou seja, a questão é pertinentemente colocada no contexto da discussão da concepção negativa da linguagem de Locke.

De facto, de acordo com Locke, as imperfeições e abusos da linguagem têm a sua raiz na natureza arbitrária de cada língua. Como Locke afirma, num parágrafo precisamente intitulado Da imperfeição das palavras do Essay: "Não tendo as palavras, naturalmente, uma significação, a ideia que cada uma representa, deve ser aprendida e retida por aqueles que trocam pensamentos e mantêm um discurso inteligível com outros, em qualquer língua”. (Essay, III, IX).

Pelo contrário, para Leibniz, é precisamente porque a linguagem não é arbitrária que é possível ultrapassar todas as imperfeições e "descobrir um remédio" (GP 5: 317) para cada uma das línguas.

Reconhecendo, embora, a importância das imperfeições e abusos da linguagem, referida por Philaleto, que discute uma a uma, Leibniz defende, de facto, dois argumentos centrais: 1. as imperfeições listadas pró-Philaleto não advêm das próprias línguas, mas são da responsabilidade dos sujeitos humanos que as usam; não são, portanto, inerentes às línguas humanas, mas uma consequência que decorre do seu uso defeituoso, ou seja, da "negligência" (Nouveaux Essais III, IX § 9) com que os homens as usam; 2. está, pois, ao alcance dos homens a possibilidade de introduzir modificações, de preencher lacunas e fixar indeterminações, de ultrapassar ambiguidades e estabilizar o significado das palavras (GP 5: 317-318, 320-321).

As soluções propostas por Leibniz - basicamente, o reconhecimento e a exploração das qualidades da escrita e das potencialidades da definição - são todas internas à própria linguagem; são processos que emergem do campo de possibilidades que a própria linguagem nos abre. Porquê? Em consequência de duas teses centrais que Leibniz expressa de forma 
clara nos Nouveaux Essais, tal como em muitos outros textos: as línguas são "o melhor espelho da mente humana" (Nouveaux Essais III, VIII, § 6) e "os mais antigos monumentos da espécie humana" (Nouveaux Essais III, IX, § 10). Ou seja, porque as línguas não são arbitrárias, mas, pelo contrário, são motivadas, tanto ao nível das suas estruturas gramaticais (que espelham as estruturas lógicas da razão humana), como na sua origem perdida, na espessura presente do seu vocabulário, nas suas palavras expressivas, na sua transparência indicativa, na sua radical abertura ao mundo, no qual elas foram criadas e que nelas está expresso.

Contrariamente a Locke, cujo objectivo é afirmar o efeito de opacidade que qualquer língua, em virtude da sua arbitrariedade, introduz entre a realidade e a mente humana, Leibniz, não só isenta as línguas naturais, lançando a culpa pelas suas imperfeições para o uso incorrecto que delas fazem os sujeitos humanos, mas também (porque começa pela tese, oposta à de Locke, da origem motivada das línguas naturais), tenta mostrar como, nos dois níveis - o sintáctico e o morfológico -, em vez de ocultar a realidade que nomeia, a língua se torna no espaço da penetração racional e prospectiva dessa realidade, o único medium que o homem tem à sua disposição para promover e clarificar o seu conhecimento do mundo.

\section{Não-Arbitrariedade em Leibniz}

Mas a tese da não-arbitrariedade da linguagem não é apenas apresentada por Leibniz em contexto polémico, como refutação da posição de Locke. Pelo contrário, é uma consequência dos dois grandes princípios da metafísica leibniziana, os princípios da razão suficiente e da harmonia preestabelecida.

A nosso ver, a tese da não-arbitrariedade da linguagem é mesmo a tese central da filosofia da linguagem de Leibniz, cumprindo aí o papel de uma espécie de ideia reguladora que atravessa todas as investigações linguísticas leibnizianas. Uma tese que, na nossa opinião, pode também ser vista como dando unidade e coerência aos três diferentes e aparentemente contraditórios projectos linguísticos de Leibniz: a) o estudo (e aperfeiçoamento) das línguas naturais (nomeadamente, o alemão), nas quais Leibniz descobre - e elogia -, tanto a riqueza etimológica, como a ainda presente motivação do seu vocabulário; b) a busca de uma Gramática Racional, na base de uma estrutura universal profunda, subjacente às 
particularidades gramaticais das várias línguas nacionais; e c) a construção de uma Língua Universal, dotada de uma similar (ou até mais elevada) natureza representativa.

Como procurámos mostrar num outro lugar (POMBO, 1997), o propósito fundamental de Leibniz seria investigar a origem motivada das línguas naturais, tanto ao nível do seu vocabulário (especialmente, o alemão) e da estrutura profunda subjacente às suas particularidades gramaticais (Gramática Racional), tentar compreender a sua origem, compreender os seus mecanismos, determinar as suas leis e, posteriormente, aplicar essas descobertas na construção de uma nova língua filosófica, igualmente motivada. Ou seja, usar esse conhecimento para (re)construir essa motivação numa língua artificial, na qual seria possível, de certo modo, repetir (e, até mesmo, aperfeiçoar) algo que já teria sido alcançado nas línguas naturais.

Neste sentido, podemos facilmente compreender a razão pela qual Leibniz explorou tantos tipos de motivação nas línguas naturais, quer ao nível do seu vocabulário, distinguindo e tentando perceber o segredo e a raiz originária das suas diferentes formas de motivação, como da estrutura universal subjacente às particularidades gramaticais de cada língua natural, que Leibniz tão profundamente investigou, no contexto dos seus projectos para uma Gramática Racional.

É também fácil perceber porquê, no projecto de uma Characteristica Universalis, o objectivo de Leibniz seja conseguir que os signos, para além da operatividade (ou capacidade funcional, no interior do sistema formal), sejam também naturais, representativos ou directamente abertos para a realidade que eles são supostos dizer. Assim se compreende, também, que Leibniz tenha perseguido tantos modelos com o objectivo de alcançar essa representatividade para os signos característicos, que tenha explorado tantos modos diferentes de alcançar essa representatividade? ${ }^{7}$

Mesmo que cada um destes modelos (que aqui é impossível sequer referir) tenha provado ser incompleto e insuficiente, o próprio facto de Leibniz ter delineado tantas estratégias e hesitado, até ao final da sua vida, em relação ao sistema de signos a adoptar, esse facto pode ser lido como sinal da importância crucial que Leibniz atribuiu ao estabelecimento desse requisito. Facto que nos dá também a marca - e o perfil complexo, difícil e intrincado de uma verdadeira teoria filosófica em processo de crescimento e alargamento problemático.

\footnotetext{
${ }^{7}$ Para uma apresentação desenvolvida deste tema, Pombo (1997, p. 223-254).

InCID: R. Ci. Inf. e Doc., Ribeirão Preto, v. 2, n. 1, p. 16-30, jan./jun. 2011.
} 


\section{Nota conclusiva}

Uma última questão merece ser colocada: como explicar que, não tendo uma teoria da linguagem desenvolvida, Espinoza tenha afirmado com tanta veemência a importância de um estilo filosófico?

Sabemos que Espinoza usa, de forma intencional e explícita, uma metodologia dedutiva para o estabelecimento do seu sistema, no qual, a partir de princípios primeiros autoevidentes (hipotéticos) e com a ajuda de definições, scholium e corolários, deduz a natureza da humanidade. A questão é a seguinte: como explicar que Espinoza, sem ter dado uma especial atenção aos temas linguagem, tenha deixado um monumento tão perfeito como a Ethica, onde tenta aplicar o estilo que ele mesmo elegera?

A comparação com Leibniz é aqui de novo muito clarificadora. De facto, contrariamente ao que poderíamos esperar, enquanto Espinoza elegeu um estilo particular "more geometrico" - como a forma necessária e adequada que a filosofia deveria procurar, pelo contrario, Leibniz, para quem a linguagem é um item central, afirma que qualquer estilo pode ser usado, desde que a verdade e a claridade estejam garantidas ${ }^{8}$.

A nossa resposta passa pela tese, aparentemente paradoxal, segundo a qual é porque o sistema de Espinoza não reservava nenhum lugar especial ao problema da linguagem que, justamente, Espinoza estava tão consciente do género literário que a filosofia devia adoptar.

Porque a linguagem é pensada por Espinoza como um obstáculo, e porque, além disso, Espinoza é um convencionalista, ele tem que estabelecer um consenso inicial, ou seja, tem que fundar o texto filosófico num princípio (ou começo) transparente. Nesta perspectiva se pode dizer que Espinoza procura a natureza divina e intuitiva dos primeiros princípios, origem e fonte de todas as ideias, causa de todos os seres, e tenta conservar essa verdade pelo rigor estrito das cadeias dedutivas, procurando assim fazer surgir, não uma grande variedade de textos e outras performances linguísticas, mas um conjunto arquitectónico como a Ethica suprema obra-prima da sua vida contemplativa.

\footnotetext{
${ }^{8}$ Reconhecendo, embora, a importância da elegância para capturar a atenção e facilitar a memória do leitor, Leibniz não deixa de considerar que as qualidades fundamentais do discurso filosófico são a clareza e a verdade (GP 4: 138-139). Sobre este tema, o nosso estudo Pombo (1996).
} 
Leibniz, pelo contrário, sendo um defensor da natureza cognitiva da linguagem e da sua abertura à realidade, pode apostar na transmissão gradual do significado, na exploração e proliferação heurística das potencialidades da linguagem, pode tentar esgotar o horizonte potencial dos significados anunciados por cada signo, por cada palavra, por cada frase, por cada escrito, por cada género, por cada estilo, ou seja, Leibniz pode estar, sobretudo, interessado na exploração activa e sistemática do dizível, no desenvolvimento e na explicação progressiva e contínua do que está implícito no universo de sentido que estrutura a razão e a sua linguagem.

Se em Espinoza existe uma ruptura clara entre verdade e significado - distinção que, como vimos, está na origem da "invenção" da sua concepção imanente do significado - ou seja, se em Espinoza deve existir uma ruptura profunda entre intuição e texto, entre razão e linguagem, pelo contrário, em Leibniz, o significado é o caminho para a verdade, ou seja, a linguagem é a via para o conhecimento.

Esta é, a nosso ver, a "grande invenção de Leibniz": verdade e significado têm unicamente uma diferença de grau.

\section{Referências}

ESPINOZA. Opera: Auftrag der Heidelberger Akademie der Wissenschaften hrsg, Von Carl Gebhardt. Heidelberg : Carl Winters Universitaetsbuchhandlung, 1972. 4 Baende.

GUÉROULT, M. Spinoza II: l'âme: ethique, 2. Paris: Aubier-Montaigne, 1974. (Analyse et Raisons, 18).

GUSDORF, G. Les origines de l'herméneutique. Paris: Payot, 1988.

LEIBNIZ, G. W. Leibniz. mathematische schriften: Hrsg. v. Carl Immanuel Gerhardt: 1-7. Hildesheim: Olms, 1962. (GM)

Die philosophischen schriften von Gottfried Wilhelm Leibniz:. Hrsg v. Carl Immanuel Gerhardt: 1-7. Hildesheim: Olms, 1960. (GP)

LÉVINAS, E. L’au-delà du Verset: lectures et discours talmudiques. Paris: Minuit, 1982.

LOCKE, J. An essay concerning humane understanding in four books. 5th. Ed., with large additions. Ed. with an introduction by John W. Yolton. Londres: Dent, 1972.

POMBO, O. The place of the dissertatio de stylo philosophico nizolii in the leibnizian praise of the German language. In: FERRARA, M. T. Italia ed Europa nella Linguistica del 
Rinascimento. Roma: Franco Cosimo Panini Editore / Istituto di Studi Rinascimentali, 1996. v. II, p. 57-67.

Leibniz e o problema de uma língua universal. Lisboa: JNICT, 1997.

Palavra e esplendor do mundo. Lisboa: Fim de Século, 2010.

ZAC, S. Spinoza et le langage. Giornale Critico Della Filosofia Italiana, n. 56, p. 612-633, 1977.

Artigo submetido em: 04 mar. 2011

Artigo aceito em: 08 abr. 2011 